Fikroh : Jurnal Pemikiran dan Pendidikan Islam

Volume. 14, Number. 2, Juli 2021

p-ISSN : 2087-7501, e-ISSN : 2715-4459

Hlm : 201-220

Journal Home Page : https://jurnal.stai-alazharmenganti.ac.id/index.php/fikroh

\title{
IMPLEMENTASI PROGRAM FULL DAY SCHOOL DALAM MENINGKATKAN AKHLAK PESERTA DIDIK
}

\author{
Siti Ainun Jariah \\ Institut Pesantren KH. Abdul Chalim, Pacet Mojokerto, Indonesia \\ Stainunjariyah99@,gmail.com \\ Ishmatun Nihayah \\ Institut Pesantren KH. Abdul Chalim, Pacet Mojokerto, Indonesia \\ ishmahnihayah@gmail.com
}

\begin{abstract}
This article aims to explain and analyze the process of implementing the full day school program at the state high school 1 Pacet and the implementation of the full day school program in improving the morals of students. This article uses a type of field research which is classified into qualitative descriptive. The data collection techniques used interview methods, observation methods and documentation methods. The data analysis technique uses data reduction, data presentation and conclusion drawing. The results of this study are: 1) Implementation of the full day school program in schools. (a) The implementation of learning starts from 06:45-15:30 with two breaks. (b) The implementation of learning is carried out all day for interior and additional material, (c) Teaching staff and placement of students in the morning class are distinguished in the afternoon class, (d) The implementation of learning in the afternoon class is mostly carried out outside the classroom so that students do not feel bored. 2) Meanwhile, the implementation of the Full Day School Program in Improving the Morals of Students at Pacet 1 State High School, namely: (a) There is an addition and strengthening of religion where the material is directly related to morals, (b) There are excellent programs such as: education designed based on monotheism, education that is not limited to theory and which is easy for students to apply in everyday life. (c) The methods used are: the method of habituation, exemplary, giving advice, studying verses and hadith, and approach methods.
\end{abstract}

Keywords: Implementation of Learning; Full Day School; Student Morals. 


\begin{abstract}
Abstrak
Artikel ini bertujuan untuk menjelaskan dan menganalisis proses pelaksanaan program full day school di sekolah menengah atas negeri 1 Pacet dan implementasi program full day school dalam meningkatkan akhlak peserta didik. Artikel ini menggunakan jenis penelitian lapangan (field research) yang digolongkan ke dalam deskriptif kualitatif. Adapun teknik pengumpulan data menggunakan metode wawancara, metode observasi dan metode dokumentasi. Teknik analisis data menggunakan reduksi data, penyajian data dan penarikan kesimpulan. Hasil dari penelitia ini adalah: 1) Pelaksanaan program full day school di sekolah. (a) pelaksanaan pembelajaran dimulai dari pukul 06:45-15:30 denggan istirahat dua kali.(b) pelaksanaan pembelajaran dilaksanakan seharian penuh untuk pedalaman dan penambahan materi,(c) tenaga pengajar dan penempatan peserta didik di kelas pagi dibedakan di kelas sore,(d)pelaksanaan pembelajaran di kelas sore lebih banyak dilaksanakan diluar kelas agar peserta didik tidak merasa bosan. 2)sedangkan Implementasi Program Full Day School Dalam Meningkatkan Akhlak Peserta Didik Di Sekolah Menengah Atas Negeri 1 Pacet yaitu :(a) adanya penambahan dan penguatan agama dimanamaterinya yang berkaita langsung dengan akhlak,(b) adanya program-program unggulan seperti:pendidikan yang dirancang berbasis tauhid,pendidikan yang tidak sebatas teori dan yang mudah di terapkan peserta didik dalam kehidupan sehari-hari.(c)adapun metode-metode yang digunakan ialah: metode pembiasaan, keteladanan, pemberian nasehat,telaah ayat dan hadist,dan metode pendekatan.
\end{abstract}

Kata kunci: Implementasi Pembelajaran; Full Day School; Akhlak Peserta Didik.

\title{
A. Pendahuluan
}

Pendidikan merupakan suatu kebutuhan yang sangat penting bagi kehidupan umat manusia. Pendidikan dapat membentuk kepribadian peserta didik dimasa yang akan datang dan sekaligus juga mempunyai fungsi untuk mengembangkan kemampuan serta meningkatkan kualitas kehidupan manusia Indonesia dalam rangka mewujudkan tujuan Negara Kesatuan Republik Indonesia ${ }^{1}$. Salah satu tujuan Negara Kesatuan Republik

\footnotetext{
${ }^{1}$ Ahmad Afif, 'Model Pengembangan Pendidikan Islam Berbasis Multikultural', Tadris: Jurnal Pendidikan Islam 7, No. 11 (2013): Http://Www.Ejournal.Stainpamekasan.Ac.Id/Index.Php/Tadris/Article/View/375/0; Ahmad Fauzi, 'Inovasi Pembelajaran Ilmu Falak Menggunakan Codacc Learning', Edukasia: Jurnal Penelitian Pendidikan Islam 14, No. 1 (24 June 2019): 157-78, Https://Doi.Org/10.21043/Edukasia.V14i1.4958; Hasan Baharun And Rohmatul Ummah, 'Strengthening Students' Character In Akhlaq Subject Through Problem Based Learning Model', Tadris: Jurnal Keguruan Dan Ilmu Tarbiyah 3, No. 1 (29 June 2018): 21-30, Https://Doi.Org/10.24042/Tadris.V3i1.2205.
} 
Indonesia yang tercantum dalam UUD 1945 adalah "Mencerdaskan kehidupan bangsa". Hal tersebut di cantumkan lebih lanjut pada batang tubuh UUD 1945 pasal 31 ayat 3 yang mengatur mengenai masalah pendidikan di Indonesia bahwa:

"Pemerintah mengusahakan dan menyelenggarakan satu pendidikan nasional, yang meningkatkan keimanan dan ketakwaan serta akblak mulia dalam rangka mencerdaskan kehidupan bangsa, yang diatur dengan undang-undang” (UUD 1945 Pasal 31 Ayat 3). ${ }^{2}$

Pendidikan memiliki banyak masalah saat ini, salah satunya yaitu masalah tentang suatu jenjang serta satuan pendidikan pada mutu pendidikan ${ }^{3}$. Beberapa usaha untuk meningkatkan mutu pendidikan telah dilakukan seperti halnya dengan cara melakukan pelatihan dan peningkatan profesionalisme guru, memperbaiki sarana dan prasarana pendidikan, serta meningkatkan mutu manajemen sekolah. implementasi telah mengacu kepada tindakan guna mencapai tujuan yang ditetapkan pada suatu keputusan ${ }^{4}$. Tindakan ini guna untuk merubah keputusan-keputusan menjadi pola operasional serta agar tercapainya perubahan-perubahan baik besar atau kecil sebagaimana yang telah diputuskan sebelumnya. Implementasi pada hakikatnya juga merupakan upaya pemahaman apa yang seharusnya terjadi setelah program dilaksanakan. ${ }^{5}$

Suatu proses untuk menuju ke arah yang lebih baik maka perlu adanya sebuah perbaikan serta penguatan dengan mengubah pengetahuan, diharapkan sehingga nantinya

\footnotetext{
2 Siti Maselah Polpoke, 'Implementasi Program Full Day School Dalam Peningkatan Kedisiplinan Peserta Didik Di Smp Islam Terpadu ( It ) As-Salam Ambon’ 1, No. 1 (2019): 2.

${ }^{3}$ Malik Fatoni, "Peran Kepala Madrasah Dalam Meningkatkan Mutu Guru Di Mts Nurul Falah Talok Kresek Kabupaten Tangerang," Tarbawi: Jurnal Keilmuan Manajemen Pendidikan 3, No. 02 (31 Desember 2017): 168-82, Https://Doi.Org/10.32678/Tarbawi.V3i02.1787; Tri Adi Muslimin Dan Ari Kartiko, "Pengaruh Sarana Dan Prasarana Terhadap Mutu Pendidikan Di Madrasah Bertaraf Internasional Nurul Ummah Pacet Mojokerto," Munaddhomah: Jurnal Manajemen Pendidikan Islam 1, No. 2 (2020): 75-87, Https://Pasca.Jurnalikhac.Ac.Id/Index.Php/Munaddhomah/Article/View/30.

4 Barirohmah Barirohmah Dan Subiyantoro Subiyantoro, "Iso 9001:2008 Quality Management System In Education," Nazhruna: Jurnal Pendidikan Islam 4, No. 2 (25 Juli 2021): 353-61, Https://Doi.Org/10.31538/Nzh.V4i2.1485; Siti Maryam Munjiat, "Islamic Education In Pesantren: Between Quality, Idealism, Or Capitalization," Syaikbuna: Jurnal Pendidikan Dan Pranata Islam 12, No. 1 (14 Maret 2021): 1-13, Https://Doi.Org/10.36835/Syaikhuna.V12i1.4370; Siti Rafiah Abd Hamid, Sharifah Syed Hassan, Dan Nik Ahmad Ismail, "Teaching Quality And Performance Among Experienced Teachers In Malaysia," Australian Journal Of Teacher Education 37, No. $11 \quad(1 \quad$ November 2012), Https://Doi.Org/10.14221/Ajte.2012v37n11.2.

${ }^{5}$ D Mulyadi, Perilaku Organisasi Dan Kepemimpinan Pelayanan (Bandung: Alfbeta, 2015).
} 
Siti Ainun Jariah \& Ishmatun Nihayah

bisa menyempurnakan subuah potensi yang ada pada manusia disebut dengan pendidikan. ${ }^{6}$ Pendidikan sendiri tidak terbatas, baik ruang serta waktu dan bisa dilaksanakan di manapun dan kapanpun, agar dapat bisa berlangsung seumur hidup. ${ }^{7}$ maka dari itu, agar bisa dapat mengungkapkan pengalaman, pikiran, perasaan, bereksplorasi dan berekspresi maka peserta didik harus selalu di beri dukungan dan motivasi oleh guru untuk membentuk bakat yang dimiliki oleh peserta didik agar bisa maksimal salah satu sebagai bentuk usaha dalam pengembangan potensi yang ada pada peserta $\operatorname{didik}^{8}$.

Proses pembelajaran dilakukan dalam kelas dan terintegrasi dalam sebuah program yang terencana ${ }^{9}$. Sistem kependidikan ini begitu penting terhadap suatu lembaga kependidikan, dikarenakansistem yaitu suatu hal mendasar dan tidak di anggap memiliki fungsi tersendiri. Sistem kependidikan sangat membantu jalannya pendidikan sehingga menjadi panduan dalam alur pendidikan tersebut. ${ }^{10}$ Pendidikan yaitu suatu proses peralihan pengetahuan secara terstruktur dari seseorang kepada orang lain sesuai dengan aturan yang telah ditetapkan oleh ahlinya. Dengan adanya pengiriman pengetahuan sehingga dapat merubah tingkah laku, pola pikir dan kepribadian dalam pendidikan yang formal dan pendidikan informal. ${ }^{11}$

Semua sekolah dari jenjang pendidikan Sekolah Dasar sampai Sekolah Menengah Atas Negeri mampu bersaing dalam menciptakan sebuah sistem pendidikan yang mana bisa atau mampu bertahan hidup pada zaman sekarang ini, salah satunya yaitu program full day school $^{12}$. Full day school yaitu sebuah model kependidikan alternatif, yang mana peserta didik

\footnotetext{
${ }^{6}$ Muhamad Arif Dan Eka Fitriyanti Handayani, "Budaya Literasi Madrasah Ibtidaiyah (Studi Kasus Madrasah Ibtidaiyah Miftahul Ulum Kesamben Wetan Driyorejo Gresik)," Modeling: Jurnal Program Studi Pgmi 7, No. 2 (2020): 198-220.

${ }^{7}$ Roqip, Ilmu Pendidikan Islam (Yogyakarta: Pt. Lkis Printing Cemerlang, 2019), 14.

8 Muhammad Anas Ma`Arif And Eka Deni Sulistyanik, 'Pengembangan Potensi Peserta Didik Dalam Pembelajaran Pendidikan Agama Islam Berbasis Kecerdasan Majemuk (Multiple Intelligence)', Al-Tarbawi AlHaditsab: Jurnal Pendidikan Islam 4, No. 2 (31 December 2019), Https://Doi.Org/10.24235/Tarbawi.V4i2.5216; Ahmad Atabik, 'Pendidikan Dan Pengembangan Potensi Anak Usia Dini', Thufula: Jurnal Inovasi Pendidikan Guru Raudhatul Athfal 2, No. 1 (2018): 149-66.

9 Saifuddin Chalim, Gatot Sujono, And Fadly Usman, 'Trend Analysis Based Educator Planning', Nazhruna: Jurnal Pendidikan Islam 3, No. 2 (8 August 2020): 273-84, Https://Doi.Org/10.31538/Nzh.V3i2.683; Jonathan Savage, Lesson Planning: Key Concepts And Skills For Teachers (Routledge, 2014).

${ }_{10}$ Amri Khoiru Ahmadi, Proses Pembelajaran Kreativ Dan Inovatif, Jakarta (Jakarta: Ptrestasi Pustaka, 2010), 13.

11 Ahmadi, 13.

12 Anis Fauzi, "Model Pelaksanaan Pendidikan Full Day School Di Mts Negeri 1 Kota Serang," Edukasia: Jurnal Penelitian Pendidikan Islam 14, No. 1 (24 Juni 2019): 221-44, Https://Doi.Org/10.21043/Edukasia.V14i1.3694.
} 
seharian berada di sekolah, melakukan proses belajar dan beribadah. Proses belajar dalam full day school tidak saja bersifat formal, tetapi terdapat juga suasana belajar yang informal dan tidak kaku serta menyenangkan bagi siswa. ${ }^{13}$ Program full day school yaitu sebuah proses pembelajaran, dilakukan lebih dominan disekolah dari pada di rumah mereka masingmasing. Sistem full day school juga ciri khas sekolah dimana belajar dengan full day school berjalan hingga sehari penuh, termasuk seluruh program belajar serta kegiatan siswa yang dilakukan di sekolah dalam bentuk sebuah sistem pendidikan dalam meningkatkan akhlak peserta didik di Sekolah Menengah Atas Negeri 1 Pacet. ${ }^{14}$

Akhlak merupakan suatu sikap yang sudah melekat dalam jiwa serta menjadi sebuah kepribadian, dan dari situlah muncul perilaku yang spontan, yang udah tanpa memerlukan pertimbangan apapun ${ }^{15}$. Bahwa semuanya dapat ditentukan oleh kondisi jiwa yang pelakunya berupaka tingkah laku, perangai dan tabiat. ${ }^{16}$ Akhlak yaitu sifat yang terdapat dalam jiwa (manusia) yang memunculkan tindakan-tindakan mudah serta gampang tanpa memerlukan pemikiran atau pertimbangan. ${ }^{17}$

Meningkatkan akhlak sama hal nya dengan tujuan pendidikan, karena banyak dijumpai bahwa tujuan pendidikan adalah untuk membentuk dan meningkatkan akhlak peserta didik, karena pendidikan budi pekerti dan akhlak merupakan jiwa dan tujuan dalam pendidikan agama Islam $^{18}$. Meningkatkan akhlak merupakan sebagai upaya dan usaha yang sungguh-sugguh dalam rangka meningkatkan akhlak anak dengan menggunakan sarana pendidikan dan pembinaan yang terprogram dengan baik dan bersungguh-sungguh.

\footnotetext{
13 Siti Mujayannah, Efektivitas Sistem Full Day School Dalam Pembentukan Akblak Siswa Sd Muhammadiyah Pakel Yogyakarta, 2013.

${ }^{14}$ Ida Nurhayati, 'Penerapana Sistem Pembelajaran Fun Dan Full Day School Untuk Meningkatkan Religious Peserta Didik Di Sdit Al Islam Kudus', Jurnal Teknologi Pendidikan Dan Pembelajaran, 2014, 238.

15 Muhammad Amri, Saharuddin Saharuddin, And La Ode Ismail Ahmad, 'The Implementation Of Islamic Education: The Process Of Instilling Akhlakul Karimah (Noble Characters) For Madrasah Tsanawiyah Students', Tadris: Jurnal Keguruan Dan Ilmu Tarbiyah 4, No. 1 (28 June 2019): 117-25, Https://Doi.Org/10.24042/Tadris.V4i1.4070; Rony And Siti Ainun Jariyah, 'Urgensi Pendidikan Karakter Dalam Membentuk Akhlak Peserta Didik', Tafkir: Interdisciplinary Journal Of Islamic Education 1, No. 1 (2020): 79-100, Https://Doi.Org/10.31538/Tijie.V1i1.18.

${ }^{16}$ Adjat Sudrajat, Pendidikan Agama Islam Di Perguruan Tinggi Uum (Yogyakarta: Uny Pers, 2008), 88.

${ }^{17}$ Robingatun, "Peran Tarekat Dalam Membangun Karakter Bangsa," Empirisma 1 (2012).

18 Ari Kartiko And Edy Kurniwan, 'Metode Bercerita Dengan Teknik Role Playing Untuk Menumbuhkan Akhlak Mulia', Nazhruna: Jurnal Pendidikan Islam 1, No. 2 (21 August 2018): 201-22, Https://Doi.Org/10.31538/Nzh.V1i2.52; Andika Aprilianto And Wahyuni Mariana, 'Permainan Edukasi (Game) Sebagai Strategi Pendidikan Karakter', Naz̧hruna: Jurnal Pendidikan Islam 1, No. 1 (5 September 2018): 139-58, Https://Doi.Org/10.31538/Nzh.V1i1.47.
} 
Siti Ainun Jariah \& Ishmatun Nihayah

Meningkatkan akhlak peserta didik dilakukan dengan asumsi bahwa akhlak merupakan sebuah hasil pembinaan dan hal tersebut tidak akan terjadi dengan sendirinya ${ }^{19}$. Sedangkan Asnil Aida Ritonga berpendapat bahwa "Akhlak yaitu suatu keadaan yang timbul timbul jiwa yang dari padanya timbul perbuatan-perbuatan yang mudah, tanpa proses pemikiran, pertimbangan dan penelitian. ${ }^{20}$

Program full day school yang ada di Sekolah Menengah Atas Negeri 1 Pacet terdapat dalam berbagai materi serta berbagai kegiatan tambahan dalam menunjang prestasi tiap siswa dan meningkatkan akhlak siswa menggunakan model pembelajaran yang disampaikan dengan kurikulum yang umum dan terdapat pendidikan agama di sekolah. Dimana siswa akan menunjukan akhlak yang ramah kepada tamu, disiplin saat mata pelajaran dan patuh terhadap aturan sekolah serta peraturan pada saat mengikuti pelajaran di kelas. Sekolah juga harus lebih mengoptimalkan penerapan program full day school dengan lebih meningkatkan kepada akhlak siswa tersebut.

\section{B. Metode Penelitian}

Pendekatan yang digunakan dalam penelitian ini yaitu pendekatan penelitian kualitatif. Menururt Moleong yang memaknai penelitian kualitatif sebagai penelitian yang bertujuan untuk memahami fenomena yang dialami oleh subjek penelitian. Lebih pas dan cocok digunakan untuk meneliti hal-hal yang berkaitan dengan penelitian perilaku, sikap, motivasi, persepsi dan tindakan subjek. Dengan kata lain, jenis penelitian tersebut, tidak bisa menggunakan metode kuantitatif ${ }^{21}$.

Sedangkan jenis penelitian dalam penelitian ini yaiu penelitian field research yang mana dipandang sebagai penelitian yang menghasilkan gambaran berupa kalimat baik secara

\footnotetext{
${ }^{19}$ Niswatun Hasanah, 'The Role Of Madrasah Ibtidaiyah In Building Student Characters In The Era Of The 4.0 Industrial Revolution', Nąhruna: Jurnal Pendidikan Islam 4, No. 2 (23 July 2021): 310-19, Https://Doi.Org/10.31538/Nzh.V4i2.1304; Nana Herdiana Abdurrahman, 'Character Education In Islamic Boarding School- Based Sma Amanah', Jurnal Pendidikan Islam 2, No. 2 (21 June 2016): 287-305, Https://Doi.Org/10.15575/Jpi.V2i2.791.

${ }^{20}$ Irwan Asnil Aidah Ritonga, Tafsir Tarbawi (Bandung: Cita Pustaka Media, 2013); Muhamad Arif, "Adab Pergaulan Dalam Perspektif Al-Ghazâlî: Studi Kitab Bidâyat Al-Hidâyah," Islamuna: Jurnal Studi Islam 6, No. 1 (20 Juni 2019): 64, Https://Doi.Org/10.19105/Islamuna.V6i1.2246; Muhamad Arif, "Konsep Etika Guru Perspektif Abuya As-Sayyid Muhammad Alwi Al-Maliki Dan Relevansinya Di Era Millenial," Fikrotuna; Jurnal Pendidikan Dan Manajemen Islam 12, No. 2 (Desember 2020): 1641-65, Https://Doi.Org/10.32806/Jf.V12i02.4064.

${ }^{21}$ Lexy J.Moleong, Metode Penelitian Kualitatif (Bandung: Remaja Rosda Karya, 2013).
} 
tertulis maupun lisan terhadap kasus yang akan di teliti. Penelitian kualitatif merupakan penelitian sebagai suatu proses penyelidikan dalam memahami masalah sosial berdasarkan pada penciptaan gambaran holistik lengkap yang dibentuk dengan kata-kata, kemudian melaporkan pandangan informan secara terperinci dan disusun dalam latar alamiah.

Tempat penelitian ini bertempat di Sekolah Menengah Atas Negeri 1 Pacet dan informan dari penelitian ini melibatkan kepala Sekolah, Guru, Staff TU dan beberapa siswa Sekolah Menengah Atas Negeri 1 Pacet. Teknik pengumpulan data ini menggunakan observasi, wawancara, dan dokumentasi. Tehnik analisis data mengikuti model yaitu dengan 1) reduksi data, 2) penyajian data dan, 3) verivikasi dan penarikan kesimpulan ${ }^{22}$.

\section{Hasil dan Pembahasan}

Lembaga pendidikan Sekolah Menengah Atas Negeri 1 Pacet Mojokerto berdiri tahun 2004 dengan kepala sekolah yaitu Bapak Drs. Masyhudi, M.M. Pada masa jabatan Bapak Masyhudi tidak memiliki fasilitas gedung sendiri. Sekolah Menengah Atas Negeri 1 Pacet Mojokerto ini menempati Sekolah Menengah Pertama Negeri 1 Pacet sebagai pembelajaran yang mana mereka bergantian dengan SMP Negeri 1 Pacet dilaksanakan pada pagi sampai siang hari kemudian Sekolah Menengah Atas negeri 1 Pacet pembelajarannya dilaksanakan pada sore hari, kegiatan pembelajaran tersebut berlangsung pada tahun 2004 hingga tahun $2005 .^{23}$

Maka dari itu, para peserta didik mengikuti ujian nasional di Sekolah Menegah Pertama Negeri 1 Pacet Mojokerto. Ujian pada pertama kali dilaksanakan mencapai prosentase $100 \%$ kelulusan dengan peserta didik berjumlah 87 orang. Setelah tahun 2005 Sekolah Menengah Atas negeri 1. Pacet Mojokerto sudah pisah dari SMPN 1 Pacet, sudah mulai mendirikan gedung sendiri. ${ }^{24}$

Lingkungan Sekolah Menengah Atas Negeri 1 Pacet Mojokerto berdiri pada lereng pegunungan dengan suasana yang sangat sejuk, meskipun sekolah Sekolah Menengah Atas negeri 1 Pacet Mojokerto ini termasuk sekolah umum dibawah DIKNAS tetapi produksi

\footnotetext{
22 Matthew B. Miles, A. M. Huberman, Dan Johnny Saldaña, Qualitative Data Analysis: A Methods Sourcebook, Third Edition (Thousand Oaks, Califorinia: Sage Publications, Inc, 2014); John W. Creswell, Qualitative Inquiry \& Research Design: Choosing Among Five Approaches, 2nd Ed (Thousand Oaks: Sage Publications, 2007).

${ }^{23}$ Sman 1 Pacet - Official Website (Sman1pacetmojokerto.Sch.Id)

${ }^{24} \underline{\text { Sman } 1 \text { Pacet - Official Website (Sman1pacetmojokerto.Sch.Id) }}$
} 
keluaran IMTAQ yang begitu baik dan produk IPTEK yang tidak kalah bagus pula dalam berbagai perlobaan, meskipun sekolah dipegunungan tetapi tidak kalah saing dari sekolahsekolah lain yang berada di Kota-Kota negera.

\section{Pelaksanaan Program Full Day School di Sekolah Menengah Atas Negeri 1 Pacet}

Sebagaimana data temuan penelitian dan paparan data penelitian melalui observasi, dokumentasi dan wawancara terhadap objek penelitian dapat dideskripsikan, sebagai berikut:

Penerapan full day school di Sekolah Menengah Atas negeri 1 Pacet Mojokerto merupakan wujud percampuran antara visi serta misi sekolah yaitu membentuk genereasi Islami yang unggul, yang tidak sekedar memiliki kecerdasan intelektual saja, selain itu juga memiliki emosional yang matang serta ketaatan spiritual. Yang diselenggarakan melalui pendidikan Islam secara integral dalam berbagai aspek, sebagaimana kurikulum yang diterapkan yaitu "kurikulum integral berbasis taubid". Oleh karena itu diharapkan dengan diterapkannya serta dilaksanakan full day school di Sekolah Menengah Atas Negeri 1 Pacet Mojokerto ini, dapat menetralkan antara pembelajaran umum dengan pembelajaran agama. ${ }^{25}$ Sehingga dapat membuat peserta didik tidak hanya akan mempelajari pembelajaran umum pada umumnya saja, namun di Sekolah Menengah Atas Negeri 1 Pacet Mojokerto ini memberikan pengetahuan yang lebih banyak untuk materi agama yang dibutuhkan bagi perkembangan akhlak peserta didik serta sangat berguna untuk kehidupan di masa depan siswa.

Adapun indikator yang hendak dicapai dalam perencanaan full day school di Sekolah Menengah Atas Negeri 1 Pacet Mojokerto yaitu: Cerdas dan Intelektual yaitu mencapai batas KKM untuk semua mata pelajaran, juga suka membaca dan menulis; Matang dan Emosional yaitu mepunyai kepekan dan kepedulian antara sesama, bisa berkomunikasi dengan baik, mampu bekerja sama antar kelompok, bersih, disiplin serta percaya pada diri; Taat Spiritual yaitu memiliki akidah yang benar dan kokoh, menimbulkan keinginan serta kesadaran dalam beribadah seperti halnya solat, puasa, berdoa, dan berdzikir, terampil dan suka membaca al Quran, suka menghafal minimal Juz'Amma serta doa sehari-hari, mampu

${ }^{25}$ Dokumen Sekolah Menengah Atas Negeri 01 Pacet 
menghafal Hadis Arba'in An Nawawi, mampu menjadi imam shalat, berbusana sesuai syariat Islam. ${ }^{26}$

Dari data tersebut, dalam proses pelaksanaanya, dapat ditemukan data sebagaimana berikut:

a. Kelas Pagi: berlangsung dari jam 07.00-13.00 WIB

Di Sekolah Menengah Atas Negeri 1 Pacet Mojokerto, peserta didik masuk pukul 07:00 WIB sudah dengan wudhunya. Para peserta didik diharuskan agar berwudhu sejak dirumah ketika akan berangkat kesekolah. Bertujuan agar peserta didik terlatih dalam menjaga kesucian, karena kesucian termasuk kedalam salah satu sunnah Rosul, Selain itu, berwudhu juga bermanfaat untuk melatih peserta didik dalam memperbaiki niat mereka sejak awal (hingga sampai ke sekolah), sehingga dapat diberikan keselamatan hingga nanti sampai di sekolah. Dan juga dengan berwudhu', maka peserta didik tidak harus menambah waktu lagi untuk berwudhu.

Peserta didik akan disambut oleh bapak dan ibu guru di sekolah. Peserta didik yang laki-laki akan mencium tangan serta mengucapkan salam hormat kepada bapak guru, sementara itu peserta didik yang perempuan akan bersalaman dengan ibu guru. Hal ini adalah bentuk dari interaksi yang dilakukan oleh peserta didik dengan gurunya, sehingga kepedulian dari seorang guru akan lebih terlihat.

Setelah itu peserta didik masuk kedalam kelas, tidak lansung untuk melaksanakan proses pembelajaran, namun hanya untuk menaruh barang-barang dikelas seperti buku dan tas, setelah itu akan bersama-sama melaksanakan sholat dhuha. Pelaksanaan sholat dhuha yang diikuti oleh seluruh siswa serta dipimpin oleh salah satu peserta didik, yang memimpin ini diberi jadwal dengan teratur berdasarkan kelas.

Tujuannya agar peserta didik bisa lebih berani dalam maju kedepan atau berdiri didepan umum, dengan itu dia harus bisa memberikan contoh yang baik kepada temantemannya, dengan shalat yang khusyu', bacaannya yang lancar dan benar, serta gerakangerakan sholat yang benar. Dan dapat membiasakan peserta didik dalam melaksanakan dengan benar hingga besar nanti. Setelah melaksanakan sholat dhuha maka siswa

\footnotetext{
${ }^{26}$ Dokumen Sekolah Menengah Atas Negeri 01 Pacet
} 
melaksanakan wirid dan berdoa bersama sehingga peserta didik dapat terbiasa bahwa setiap selesai sholat maka mereka harus berdoa dan dzikir terlebih dahulu.

Setelah melaksanakan sholat dhuha, siswa lansung menuju kelas untuk melanjutkan pembelajaran dengan mata pelajaran umum. Dalam kegiatan pebelajaran dalam kelas, guru dan peserta didik selalu melakukan doa bersama. Setelah melaksanakan doa, baru guru mulai untuk berbicara kepada siswa dengan menyapa dan mengambil absen dari peserta didik. Penulis menyimpulkan bahwasanya Pada saat inilah hal-hal yang sangat penting ditemukan pada Sekolah Menengah Atas Negeri 1 Pacet Mojokerto, yang mana sekolah inilah peserta didik mengerti dan mengetahui antara nilai-nilai tauhid yang diintegrasikan dalam sebuah pembelajaran.

b. Kelas Sore : berlangsung dari jam $13.00-15.30 \mathrm{WIB}$

Begitu juga kegiatan belajar mengajar dari jam 13.00-15.30 WIB. Peserta didik setelah peserta didik melaksanakan sholat zuhur secara berjamaah, dan peserta didik melaksanakan makan siang lalu peserta didik lansung melaksanakan kelas sore. Kelas sore ini termasuk kedalam kelas dimana terdapat pembelajaran mengenai penguatan materi-materi agama (penguatan agama islam).

Pada sore hari materi agama yang diajarkan kepada siswa-siswa untuk penguatan agama yaitu tahfidzul Qur'an, Tahfidzul Hadist, Tahfidzul do'a dan tulis baca Al-Qur'an, materi penguatan agama pada sore hari ini lebih banyak kepada hafalan karena untuk bekal bagi peserta didik untuk berdakwah nantinya, namun begitu dalam kelas sore tidak begitu formal seperti pembelajaran pagi. ${ }^{27}$

Menurut keterangan diatas peneliti menyimpulkan adapun kegiatan belajar mengajar di Sekolah Menengah Atas Negeri 1 Pacet ini, di dalam kelas sore ini juga memadukan nilai tauhid pada materi pelajaran. Jika pada kelas pagi guru biasanya memadukan nilai-nilai tauhid dengan pemberian appersepsi, sementara itu di kelas sore ini guru biasanya memadukannya yaitu nilai tauhid di sela-sela hafalan dan murojaah, peserta didik dibawa guru untuk memahami kandungan ayat atau hadist yang dipelajari bersamaan dengan memasukan nilai-nilai tauhid di dalamnya dengan pembelajaran yang

\footnotetext{
${ }^{27}$ Hasil Wawancara Bapak Yusuf Selaku Guru Pai Sekolah Menengah Atas Negeri 1 Pacet Pada Jam 08.50 Tanggal 25 Januari 2021, Di Masjid Sman 1 Pacet
} 
sudah dipahami oleh peserta didik. Pada kelas sore menurut peneliti yang mana kelasnya tidak formal dan guru yang mengajarnya juga berbeda merupakan sesuatu yang tidak membuat siswa-siswa menjadi bosan dalam belajar karena juga pembelajaran sore tidak dilakukan secara formal seperti dipagi hari yang didalam kelas, namun sekolah sore juga dilakukan diluar kelas.

c. Waktu Istirahat : berlangsung jam 09.00-09.30 WIB dan jam 12.15-13.00 WIB

Adapun waktu istirahat di Sekolah Menengah Atas Negeri 1 Pacet Mojokerto terdapat 2 , yang pertama jam 09.00-09.30 WIB serta yang kedua jam 12.15-13.00 WIB. Pada jam istirahat peserta didik bisa makan bekal yang dibawah dari rumah serta sambil dengan teman-teannya bermain. Bagi yang tidak membawa bekal dari rumah, sekolah ini juga menyediakan kantin atau tempat makan dan jajan. Peneliti juga mendapatkan informasi dari hasil wawancara bersama Ibu Nanik Selaku Guru Bimbingan Konseling (BK) Di Sekolah Menengah Atas Negeri 1 Pacet bahwasanya, Peserta didik disini dibiasakan agar dapat memakan makan-makanan yang sehat, tujuanya melatih mereka agar hemat dan tidak boros. Bahkan kebersamaan antara mereka yang berteman dapat terjalin lebih erat karena semuanya itu sama dan tidak ada yang dibeda-bedakan, sehingga tidak akan membuat peserta didik membeda-bedakan dengan yang lainnya. Yang dapat membentuk akhlak lainnya yaitu peserta didik terbiasa makan dengan baik yaitu mencuci tangan, serta berdoa sebelum dan sesudah makan, makan menggunakan tangan kanan, serta makan posisi duduk. ${ }^{28}$

Selain Bahkan pada waktu istirahan, bapak dan ibu wali kelas menggunakannya waktu untuk pendampingan atau bimbingan. Cara ini dilakukan agar peserta didik yang tidak atau belum berbuat sesuai dengan aturan maka guru melakukan dengan cara memanggilnya dan diberikan bibingan kepada peserta didik tersebut. Cara ini terlihat bahwa pedulinya seorang guru terhadap murid atau peserta didiknya. Dengan cara ini, dapat membuat siswa agar dapat termotivasi dan lebih dekat dengan guru sehingga anak tersebut menjadi lebih baik dan dapat memiliki akhlak yang baik.

\footnotetext{
${ }^{28}$ Hasil Wawancara Ibu Nanik Selaku Guru Bk Sekolah Menengah Atas Negeri 1 Pacet Pada Jam 11.00 Tanggal 25 Januari 2021
} 
Di Sekolah Menengah Atas Negeri 1 Pacet ini dalam proses kegiatan belajar siswa-siswa sengaja waktunya di beda-bedakan ada yang waktu pagi dan waktu sore, dan juga tenaga pengajar dan kelas-kelasnya juga berbeda sesusai target yang lebih spesifik dengan tujuan untuk siswa-siswa lebih fokus dan maksimal dalam proses pembelajaran. Dalam hal ini dapat disimpulkan bahwa ada klasifikasi untuk kelas pagi dengan kelas sore terkait tenaga pengajar, waktu, serta kelasnya. Tujuan pengklasifikasian tersebut adalah agar peserta didik lebih fokus dan maksimal dalam mengikuti pembelajaran.

Peneliti menyimpulkan bahwa ada pembagian waktu dalam pelaksanaan program atau kegiatan pada sholat perjamaah. Tujuan pembagian kegiatan tersebut adalah agar peserta didik lebih fokus dan maksimal kegiatan. Sekolah Menengah Atas negeri 1 Pacet menerapkan full day school dengan tujuan untuk membentuk generasi Islami yang unggul sebagaimana visi dan misinya. Mengembangkan dasar kehidupan sesuai dengan agama. Kemudian peserta didik yang mengikuti full day school menjadi terbiasa melakukan hal positif karena pembiasaan dan bimbingan dari bapak ibu guru. Sehingga tertanam akhlakul karimah dalam diri peserta didik dan juga siswa-siswa leboh banyak waktu disekolah untuk proses belajar baik itu belajar tentang pelajaran umum maupun ilmu agama,

Di dalam pelaksanaan full day school, metode yang digunakan oleh pengajar atau guru sangatlah banyak, seperti dikelas pagi maupun dikelas sore. Agar pada kegiatan belajar mengajar berjalan, maka peserta didik menjadi senang dalam mengikuti pembelajaran. Tenaga pengajar di Sekolah Menengah Atas Negeri 1 Pacet Mojokerto diharuskan agar lebih kreatif sehingga peserta didik tidak bosan dan fokus dalam belajar sehingga dapat mencapai hasil yang maksimal. Metode-metode itu diantaranya yaitu metode keteladanan, metode pemberian nasehat, metode pembiasaan, metode bercerita, metode diskusi, metode hafalan. Ada juga metode pendampingan yang diterapkan pada saat jam istirahat. Metode pendampingan ini digunakan untuk pesrta didik yang dilihat belum mencapai KKM dalam proses pebelajaran. Metode telaah ayat dan hadist sering juga digunakan terutama dikelas sore. Dengan demikian bahwa metode telaah ayat dan hadis adalah metode untuk menerangkan kandungan ayat dan hadist dengan menyimak penjelasan dari guru melalui buku panduan. 
Dengan demikian, dapat peneliti simpulkan dari hasil wawancara bersama Bapak Suyanto selaku Waka Kurikulum, Bapak Rokim selaku Waka Kesiswaan, dan Bapak Yusuf Selaku Guru Pendidikan Agama Islam di Sekolah Menengah Atas Negeri 1 Pacet dan dari hasil data lapangan terkait pelaksanaan sistem full day school di Sekolah Menengah Atas Negeri 1 Pacet Mojokerto yaitu: 1) Dimulainya pelaksanaan Full Day School Di Sekolah Menengah Atas Negeri 1 Pacet dari jam 06,45-15,30, dengan memadukan pembelajaran umum dan pembelajaran agama serta pedalamam materi; 2) Pelaksanaan full day school di sekolah menengah atas negeri 1 pacet yaitu untuk menetapkan pembelajaran seharian penuh dengan susunan pembelajaran yang intensif yaitu adanya jam tambahan untuk pedalaman materi; Untuk tenaga pengajar dan penempatan siswa juga berbeda dari kelas pagi dan kelas sore, di sesuaikan dari target yang ditentukan, tujuan nya agar lebih spesifik dan peserta didik agar lebih focus dan maksimal dalam belajar; Dikelas sore pelaksanaan pembelajaran tidak hanya didalam kelas melainkan juga lebih banyak diluar ruangan/diluar kelas, tujuan nya agar peserta didik tidak merasa bosan/jenuh dan menggantuk karena sudah belajar seharian.

Dengan demikian peneliti menyimpulkan bahwasanya pelaksanaan program Full Day School Di Sekolah Menengah Atas Negeri 1 Pacet ini telah sesuai dengan teori full day school merupakan proses belajar mengajar yang dilakukan dari pagi hingga sore hari, disesuaikan dengan bobot mata pelajaran dan ditambah dengan pendalaman materi. ${ }^{29}$ full day school di Sekolah Menengah Atas Negeri 1 Pacet Mojokerto berisikan arti susunan pendidikan yang menetapkan pembelajaran serta kegiatan belajar mengajar seharian penuh dengan memadukan susunan pengajaran yang intensif yakni menambah jam pelajaran untuk mendalamkan materi pelajaran serta pengembangan diri dan kreatifitas. ${ }^{30}$

Peneliti menarik kesimpulan bahwasanya hasil dari data lapangan terkait program full day school di Sekolah Menengah Atas Negeri 1 Pacet Mojokerto ini telah sesuai dengan teori Djamaludin Ancok dan Fuad Nashori yang menjelaskan bahwa: full day school sebagian waktunya digunakan untuk program pembelajaran secara informal, tidak kaku, menyenangkan bagi peserta didik. Ini telah sama dengan yang diterapkan di Sekolah

\footnotetext{
${ }^{29}$ Baharuddin, Pendidikan Dan Psikologi Perkembangan (Jogjakarta: Ar-Ruzz Media, 2009).

${ }^{30}$ Polpoke, "Implementasi Program Full Day School Dalam Peningkatan Kedisiplinan Peserta Didik Di Smp Islam Terpadu ( It ) As-Salam Ambon,” 14-32.
} 
Menengah Atas Negeri 1 Pacet yang proses belajar sorenya secara tidak formal dan tidak didalam kelas yang membuat siswa tidak bosan belajar seharian.

Dapat membutuhkan kreativitas dan inovasi dari guru. Dengan dimulainya jam sekolah dari pagi sampai sore hari. Hal ini telah sesuai dengan yang diterapkan oleh para guru di Sekolah Menengah Atas Negeri 1 Pacet, guru memberikan inovasi yang kreatif terhadap peserta didik agar fokus dan maksimal dalam proses pembelajaran dari pagi sampai sore dengan cara memisahkan waktu pagi untuk formal dan sore untuk non formal.

Sekolah bisa leluasa mengatur jam pelajaran yang mana disesuaikan dengan bobot pelajaran dan ditambah dengan model pembelajarannya, dalam hal ini Sekolah Menengah Atas Negeri 1 Pacet juga memisahkan kelas-kelas seusai kemampuan dan tenaga pengajar juga diganti- ganti agar lebih maksimal dan tidak membosankan kalau belajar dengan guruguru yang sama terus. ${ }^{31}$

\section{ANALISIS DATA}

Berdasarkan penelitian yang dilakukan dan diperoleh oleh peneliti dari berbagai sumber, yang meliputi observasi, wawancara, dokumentasi, berikut peneliti sajikan dari beberapa temuan peneliti temukan di lapangan. Pelaksanaan Sistem Full Day School Di Sekolah Menengah Atas Negeri 1 Pacet Mojokerto Berdasarkan hasil penelitian, pelaksanaan full day school di Sekolah Menengah Atas Negeri 1 Pacet yaitu kegiatan-kegiatan siswa sejak pagi hingga sore semua diintegrasi dengan pembelajaran akhlak. Yang pertama ketika siswa datang dibiasakan untuk bersalaman dengan Bapak dan Ibu Guru dan mengucapkan salam, kedua setelah bel masuk berbunyi seluruh siswa keluar kelas masingmasing untuk berdoa dan menyanyikan lagu wajib secara central yang dipimpin oleh siswa sendiri secara bergilir.

Seluruh Bapak dan Ibu Guru mendampingi siswa dalam pelaksanaan doa pagi, adapun pelakssanaan nya sebagai berikut: 1) Dimulainya pelaksanaan Full Day School Di Sekolah Menengah Atas Negeri 1 Pacet dari jam 06,45-15,30, dengan memadukan pembelajaran umum dan pembelajaran agama serta pedalamam materi. 2) Pelaksanaan full day school di sekolah menengah atas negeri 1 pacet yaitu untuk menetapkan pembelajaran

31 Djamaludin Ancok Dan Fuad Nashori, Psikologi Islam: Solusi Islam Atas Problem Prikologi, Yogyakarta (Yogyakarta: Pustaka Belajar, 2011). 
seharian penuh dengan susunan pembelajaran yang intensif yaitu adanya jam tambahan untuk pedalaman materi. 3) Untuk tenaga pengajar dan penempatan siswa juga dibedakan dari kelas pagi dan kelas sore, di sesuaikan dengan target yang ditentukan, tujuan nya agar lebih spesifik dan peserta didik agar lebih fokus dan maksimal dalam belajar. 4) Dikelas sore pelaksanaan pembelajaran tidak hanya didalam kelas melainkan juga lebih banyak diluar ruangan/diluar kelas, tujuan nya agar peserta didik tidak merasa bosan/jenuh dan menggantuk karena sudah belajar seharian. 5) full day school sebagian waktunya digunakan untuk program pembelajaran secara informal, tidak kaku, menyenangkan bagi peserta didik.

Implementasi Program Full Day School untuk meningkatkan akhlak peserta didik Di Sekolah Menengah Atas Negeri 1 Pacet Mojokerto. Dalam upaya program full day school di Sekolah Menengah Atas Negeri 1 Pacet dalam meningkatkan Akhlak Peserta Didik pada awalnya dilakukan dengan metode kebiasaan, metode memberikan nasehat, cara yang teladan, memberikan apresiasi, memberikan pendampingan, memberikan pelajaran memahami hadis dan ayat, dan disertai dengan metode pendekatan alam. Adapun beberapa cara meningkatkan akhlak peserta didik di Sekolah Menengah Atas Negeri 1 Pacet yaitu meliputi: 1) Adanya penambahan dan penguatan agama yang materinya berkaitan langsung dengan akhlak sehingga peserta didik dapat mengaplikasikanya setiap hari. 2) Adanya program unggulan Di Sekolah Menengah Atas Negeri 1 Pacet yaitu; a) Pendidikan yang dirancang berbasis tauhid. b) Pendidikan karakter peserta didik yang tidak sebatas teori, tetapi aplikatif dan mudah diterapkan peserta didik. c) Mengenal sang maha pencipta melalui pendekatan alam.

Dalam jurnal pendidikan Islam, karangan Nor Hasan, menjelaskan bahwa yang dimaksud dengan full day school secara istilah yaitu suatu proses pembelajaran yang berlangsung secara aktif, kreatif dan transformatif selama sehari penuh bahkan selama kurang lebih $24 \mathrm{jam}^{32}$. Yang dimaksud dengan aktif disini yaitu mengoptimalisasikan seluruh potensi untuk mencapai tujuan pembelajaran secara optimal. Sedangkan sisi kreatif terletak pada optimalisasi pemanfaatan sarana dan prasarana sekaligus sistem untuk

32 Nor Hasan, "Fullday School (Model Alternatif Pembelajaran Bahasa Asing)," Tadris: Jurnal Pendidikan Islam 1, No. 1 (2006), Http://Ejournal.Stainpamekasan.Ac.Id/Index.Php/Tadris/Article/View/194. 
mewujudkan proses pembelajaran yang kondusif bagi pengembangan segenap potensi siswa $^{33}$. Adapun dari segi transformatif dalam pembelajaran Full Day School adalah proses pembelajaran yang diabadikan untuk mengembangkan seluruh potensi kepribadian siswa dengan lebih seimbang. Dan yang dimaksud dengan sistem 24 jam dimaksudkan sebagai ikhtiar bagaimana selama sehari semalam siswa melakukan aktivitas bermakna edukatif. ${ }^{34}$

Adapun metode-metode yang sering digunakan pendidik (guru) di Sekolah Menengah Atas Negeri 1 Pacet untuk meningkatkan akhlak peserta didik yaitu: 1) Metode pembiasaan Metode keteladanan 2) Metode pemberian nasehat 3) Metode pendampingan 4) Metode appersepsi 5) Metode telaah ayat dan hadist 6) Metode pendekatan.

Implementasi program full day school dalam pembentukan akhlak siswa di Sekolah Menengah Atas Negeri 1 Pacet dilakukan melalui program-program pembiasaan harian seperti shalat dhuha, dzikir pagi, hikmah pagi, tahfidz, shalat dhuhur berjamaah, pembelajara umum dan lain-lain, juga melalui pembiasaan mingguan seperti kegiatan ekstrakurikuler, infaq, dan lain-lain, dan juga melalui pembiasaan tahunan seperti khatmil Qur'an, pesantren ramadhan, mabit (malam bina iman dan taqwa, dan melalui pembiasaan incendental seperti sumbangan bencana alam, menjenguk orang sakit dan lain-lain yang bertujuan untuk melatih siswa untuk membangun jiwa sosial terhadapa sesama dalam kehidupan sosial bersama.

Implementasi program full day school dalam pembentukan akhlak siswa di Sekolah Menengah Atas Negeri 1 Pacet sesuai dengan teori Moch Lis Yulianti Syafrida Siregar bahwasanya sistem full day school sendiri yaitu merupakan pengemasan dalam hal metode belajar yang berorientasi pada kualitas pendidikan yang berlangsung selama sehari penuh dengan menggunakan integrated activity yang menyenangkan dalam pembelajaran. ${ }^{35}$

\footnotetext{
33 Eva Latipah And Dinda Awalliyatunnisa, 'Pembelajaran Pendidikan Agama Islam Secara Daring Dan Permasalahannya', Fikroh: Jurnal Pemikiran Dan Pendidikan Islam 14, No. 2 (1 July 2021): 129-57, Https://Doi.Org/10.37812/Fikroh.V14i2.150.

${ }^{34}$ Siti Ainun Jariyah, 'Urgensi Pendidikan Karakter Dalam Membentuk Akhlak Peserta Didik' 1, No. 1 (2020): 83.

35 Moch Lis Yulianti Syafrida Siregar Dan Romli, 'Manajemen Pembelajaran Di Sekolah Dasar Full Day School', Disertasi Um Malang, 2004, 31.
} 


\section{E. Simpulan}

Pelaksanaan program full day school di Sekolah Menengah Atas Negeri 1 Pacet mojokerto Dimulainya dari jam 06,45-15,30, dengan memadukan pembelajaran umum dan pembelajaran agama serta pedalamam materi yang terbagi dari jam pagi dan jam sore, jam pagi di lakukan formal dan sore non formal. Implementasi Program Full Day School dalam meningkatkan akhlak peserta didik di Sekolah Menengah Atas Negeri 1 Pacet berdasarkan hasil penelitian dapat peneliti simpulkan sebagai berikut: 1) Adanya penambahan dan penguatan agama yang materinya berkaitan langsung dengan akhlak sehingga peserta didik dapat mengaplikasikanya setiap hari. 2) Adanya program unggulan Di Sekolah Menengah Atas Negeri 1 Pacet yaitu Pendidikan yang dirancang berbasis tauhid, Pendidikan karakter peserta didik yang tidak sebatas teori, tetapi aplikatif dan mudah diterapkan peserta didik, Mengenal sang maha pencipta melalui pendekatan alam.

\section{DAFTAR PUSTAKA}

Abd Hamid, Siti Rafiah, Sharifah Syed Hassan, Dan Nik Ahmad Ismail. "Teaching Quality And Performance Among Experienced Teachers In Malaysia." Australian Journal Of Teacher Education 37, No. 11 (1 November 2012). Https://Doi.Org/10.14221/Ajte.2012v37n11.2.

Abdurrahman, Nana Herdiana. "Character Education In Islamic Boarding School- Based Sma Amanah." Jurnal Pendidikan Islam 2, No. 2 (21 Juni 2016): 287-305. Https://Doi.Org/10.15575/Jpi.V2i2.791.

Afif, Ahmad. "Model Pengembangan Pendidikan Islam Berbasis Multikultural." Tadris: Jurnal Pendidikan Islam 7, No. 1 (2013): 1-18. Http://Www.Ejournal.Stainpamekasan.Ac.Id/Index.Php/Tadris/Article/View/37 $5 / 0$.

Ahmadi, Amri Khoiru. Proses Pembelajaran Kreativ Dan Inovatif, Jakarta. Jakarta: Ptrestasi Pustaka, 2010.

Amri, Muhammad, Saharuddin Saharuddin, Dan La Ode Ismail Ahmad. "The Implementation Of Islamic Education: The Process Of Instilling Akhlakul Karimah (Noble Characters) For Madrasah Tsanawiyah Students." Tadris: Jurnal Keguruan Dan Ilmu Tarbiyah 4, No. 1 (28 Juni 2019): 117-25. Https://Doi.Org/10.24042/Tadris.V4i1.4070.

Aprilianto, Andika, Dan Wahyuni Mariana. "Permainan Edukasi (Game) Sebagai Strategi Pendidikan Karakter." Nað̧hruna: Jurnal Pendidikan Islam 1, No. 1 (5 September 2018): 139-58. Https://Doi.Org/10.31538/Nzh.V1i1.47. 
Arif, Muhamad. "Adab Pergaulan Dalam Perspektif Al-Ghazâlî: Studi Kitab Bidâyat AlHidâyah.” Islamuna: Jumal Studi Islam 6, No. 1 (20 Juni 2019): 64. Https://Doi.Org/10.19105/Islamuna.V6i1.2246.

. "Konsep Etika Guru Perspektif Abuya As-Sayyid Muhammad Alwi Al-Maliki Dan Relevansinya Di Era Millenial." Fikrotuna; Jurnal Pendidikan Dan Manajemen Islam 12, No. 2 (Desember 2020): 1641-65. Https://Doi.Org/10.32806/Jf.V12i02.4064.

Arif, Muhamad, Dan Eka Fitriyanti Handayani. "Budaya Literasi Madrasah Ibtidaiyah (Studi Kasus Madrasah Ibtidaiyah Miftahul Ulum Kesamben Wetan Driyorejo Gresik)." Modeling: Jurnal Program Studi Pgmi 7, No. 2 (2020): 198-220.

Asnil Aidah Ritonga, Irwan. Tafsir Tarbawi. Bandung: Cita Pustaka Media, 2013.

Atabik, Ahmad. "Pendidikan Dan Pengembangan Potensi Anak Usia Dini." Thufula: Jurnal Inovasi Pendidikan Guru Raudhatul Athfal 2, No. 1 (2018): 149-66.

Baharuddin. Pendidikan Dan Psikologi Perkembangan. Jogjakarta: Ar-Ruzz Media, 2009.

Baharun, Hasan, Dan Rohmatul Ummah. "Strengthening Students' Character In Akhlaq Subject Through Problem Based Learning Model." Tadris: Jurnal Keguruan Dan Ilmu Tarbiyah 3, No. 1 (29 Juni 2018): 21-30. Https://Doi.Org/10.24042/Tadris.V3i1.2205.

Barirohmah, Barirohmah, Dan Subiyantoro Subiyantoro. "ISO 9001:2008 Quality Management System In Education.” Nąhruna: Jurnal Pendidikan Islam 4, No. 2 (25 Juli 2021): 353-61. Https://Doi.Org/10.31538/Nzh.V4i2.1485.

Chalim, Saifuddin, Gatot Sujono, Dan Fadly Usman. "Trend Analysis Based Educator Planning." Nazhruna: Jurnal Pendidikan Islam 3, No. 2 (8 Agustus 2020): 273-84. Https://Doi.Org/10.31538/Nzh.V3i2.683.

Creswell, John W. Qualitative Inquiry \& Research Design: Choosing Among Five Approaches. 2nd Ed. Thousand Oaks: Sage Publications, 2007.

Fatoni, Malik. "Peran Kepala Madrasah Dalam Meningkatkan Mutu Guru Di Mts Nurul Falah Talok Kresek Kabupaten Tangerang." Tarbawi: Jurnal Keilmuan Manajemen Pendidikan 3, No. 02 (31 Desember 2017): 168-82. Https://Doi.Org/10.32678/Tarbawi.V3i02.1787.

Fauzi, Ahmad. "Inovasi Pembelajaran Ilmu Falak Menggunakan Codacc Learning." Edukasia: Jurnal Penelitian Pendidikan Islam 14, No. 1 (24 Juni 2019): 157-78. Https://Doi.Org/10.21043/Edukasia.V14i1.4958.

Fauzi, Anis. "Model Pelaksanaan Pendidikan Full Day School Di Mts Negeri 1 Kota Serang." Edukasia: Jumal Penelitian Pendidikan Islam 14, No. 1 (24 Juni 2019): 22144. Https://Doi.Org/10.21043/Edukasia.V14i1.3694.

Hasan, Nor. "Fullday School (Model Alternatif Pembelajaran Bahasa Asing)." Tadris: Jurnal Pendidikan Islam $1, \quad$ No. 1 (2006). Http://Ejournal.Stainpamekasan.Ac.Id/Index.Php/Tadris/Article/View/194. 
Hasanah, Niswatun. "The Role Of Madrasah Ibtidaiyah In Building Student Characters In The Era Of The 4.0 Industrial Revolution." Nazhruna: Jurnal Pendidikan Islam 4, No. 2 (23 Juli 2021): 310-19. Https://Doi.Org/10.31538/Nzh.V4i2.1304.

Jariyah, Siti Ainun. "Urgensi Pendidikan Karakter Dalam Membentuk Akhlak Peserta Didik" 1, No. 1 (2020): 79-100.

J.Moleong, Lexy. Metode Penelitian Kualitatif. Bandung: Remaja Rosda Karya, 2013.

Kartiko, Ari, Dan Edy Kurniwan. "Metode Bercerita Dengan Teknik Role Playing Untuk Menumbuhkan Akhlak Mulia." Nað̧bruna: Jurnal Pendidikan Islam 1, No. 2 (21 Agustus 2018): 201-22. Https://Doi.Org/10.31538/Nzh.V1i2.52.

Latipah, Eva, Dan Dinda Awalliyatunnisa. "Pembelajaran Pendidikan Agama Islam Secara Daring Dan Permasalahannya." Fikroh: Jurnal Pemikiran Dan Pendidikan Islam 14, No. 2 (1 Juli 2021): 129-57. Https://Doi.Org/10.37812/Fikroh.V14i2.150.

Lis Yulianti Syafrida Siregar Dan Romli, Moch. "Manajemen Pembelajaran Di Sekolah Dasar Full Day School.” Disertasi UM Malang, 2004.

Ma`Arif, Muhammad Anas, Dan Eka Deni Sulistyanik. "Pengembangan Potensi Peserta Didik Dalam Pembelajaran Pendidikan Agama Islam Berbasis Kecerdasan Majemuk (Multiple Intelligence)." Al-Tarbawi Al-Haditsab: Jurnal Pendidikan Islam 4, No. 2 (31 Desember 2019). Https://Doi.Org/10.24235/Tarbawi.V4i2.5216.

Miles, Matthew B., A. M. Huberman, Dan Johnny Saldaña. Qualitative Data Analysis: A Methods Sourcebook. Third Edition. Thousand Oaks, Califorinia: SAGE Publications, Inc, 2014.

Mujayannah, Siti. Efektivitas Sistem Full Day School Dalam Pembentukan Akblak Siswa SD Muhammadiyah Pakel Yogyakarta, 2013.

Mulyadi, D. Perilaku Organisasi Dan Kepemimpinan Pelayanan. Bandung: Alfbeta, 2015.

Munjiat, Siti Maryam. "Islamic Education In Pesantren: Between Quality, Idealism, Or Capitalization." Syaikhuna: Jurnal Pendidikan Dan Pranata Islam 12, No. 1 (14 Maret 2021): 1-13. Https://Doi.Org/10.36835/Syaikhuna.V12i1.4370.

Muslimin, Tri Adi, Dan Ari Kartiko. "Pengaruh Sarana Dan Prasarana Terhadap Mutu Pendidikan Di Madrasah Bertaraf Internasional Nurul Ummah Pacet Mojokerto." Munaddhomah: Jurnal Manajemen Pendidikan Islam 1, No. 2 (2020): 75-87. Https:/ / Pasca.Jurnalikhac.Ac.Id/Index.Php/Munaddhomah/Article/View/30.

Nashori, Djamaludin Ancok Dan Fuad. Psikologi Islam: Solusi Islam Atas Problem Prikologi, Yogyakarta. Yogyakarta: Pustaka Belajar, 2011.

Nurhayati, Ida. "Penerapana Sistem Pembelajaran Fun Dan Full Day School Untuk Meningkatkan Religious Peserta Didik Di Sdit Al Islam Kudus." Jumal Teknologi Pendidikan Dan Pembelajaran, 2014.

Polpoke, Siti Maselah. "Implementasi Program Full Day School Dalam Peningkatan Kedisiplinan Peserta Didik Di Smp Islam Terpadu (It) As-Salam Ambon” 1, No. 1 (2019): 14-32. 
Siti Ainun Jariah \& Ishmatun Nihayah

Robingatun. "Peran Tarekat Dalam Membangun Karakter Bangsa." Empirisma 1 (2012).

Rony, Dan Siti Ainun Jariyah. "Urgensi Pendidikan Karakter Dalam Membentuk Akhlak Peserta Didik." Tafkir: Interdisciplinary Journal Of Islamic Education 1, No. 1 (2020): 79_ 100. Https://Doi.Org/10.31538/Tijie.V1i1.18.

Roqip. Ilmu Pendidikan Islam. Yogyakarta: PT. Lkis Printing Cemerlang, 2019.

Savage, Jonathan. Lesson Planning: Key Concepts And Skills For Teachers. Routledge, 2014.

Sudrajat, Adjat. Pendidikan Agama Islam Di Perguruan Tinggi Uum. Yogyakarta: UNY Pers, 2008. 